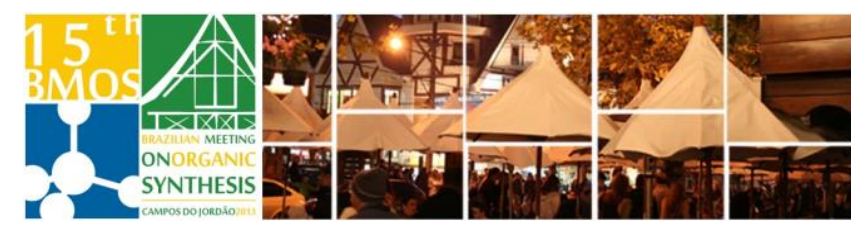

\title{
C5 atom of D-galactopyranose as a source of chirality: preliminary results
}

\author{
Maria Joselice e Silva, ${ }^{1}$ Paulo Roberto da Silva ${ }^{2}$ and Bogdan Doboszewski ${ }^{2 \star}$ \\ ${ }^{1}$ Departamento de Farmácia, Universidade Federal do Rio Grande do Norte, 59010-180 Natal, RN; \\ ${ }^{2}$ Departamento de Química and Departamento de Ciências Moleculares, Universidade Federal Rural de
}

Pernambuco, 52171-900 Recife, PE, Brasil

*bdoboszewski@hotmail.com

Keywords: chiral pool; D-galactose; stereoselective synthesis

\section{INTRODUCTION}

Carbohydrates, ${ }^{1}$ terpenes $^{2}$ and aminoacids $^{3}$ are widely used chiral-pool substrates for stereoselective synthesis. D-Galactose is a convenient compound in this context since it is the only easily available sugar furnishing its derivative, viz. 1, which displays primary $\mathrm{OH}$ group in a single protecting step. We reasoned that 1 can be further extended to get 2, which upon degradation would furnish the chiral products 3 . The stereogenic center present in $\mathbf{3}$ is the $\mathrm{C} 5$ atom in $\mathbf{1}$. The objective of this communication is to present preliminary results of such investigation.

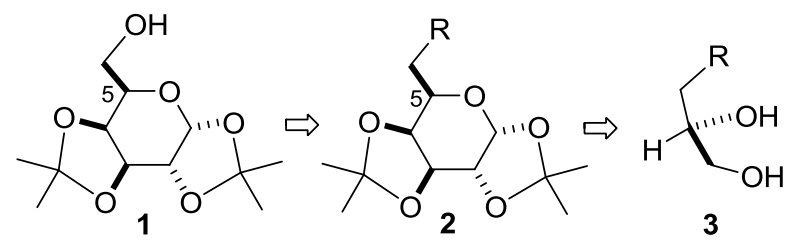

\section{RESULTS AND DISCUSSION}

The idea presented above was tested as shown in the Scheme 1 and permitted isolation of the expected diol (S)-4.
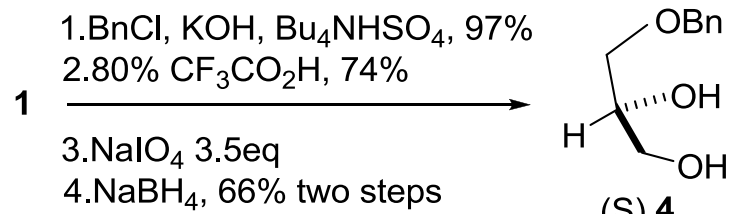

(S) 4

Scheme 1. C5 atom in the di-O-isopropylidene- $\alpha-D-$ galactopyranose 1 as a source of chirality in the glycerol 4: a model reaction.

Having confirmed the viability of the concept, an extension at the C6 position in $\mathbf{1}$ to get $\mathbf{5}$ and $\mathbf{6}$ was performed to obtain the substrates for synthesis of the $(R)$ diols 7 . The compound 5 was obtained from 1 via oxidation, two carbon atoms extension and hydrogenation. Alternatively, $\mathbf{5}$ was prepared via substitution at the $\mathrm{C} 6$ position using sodium malonate followed by dealquilative decarboxylation (Scheme 2).

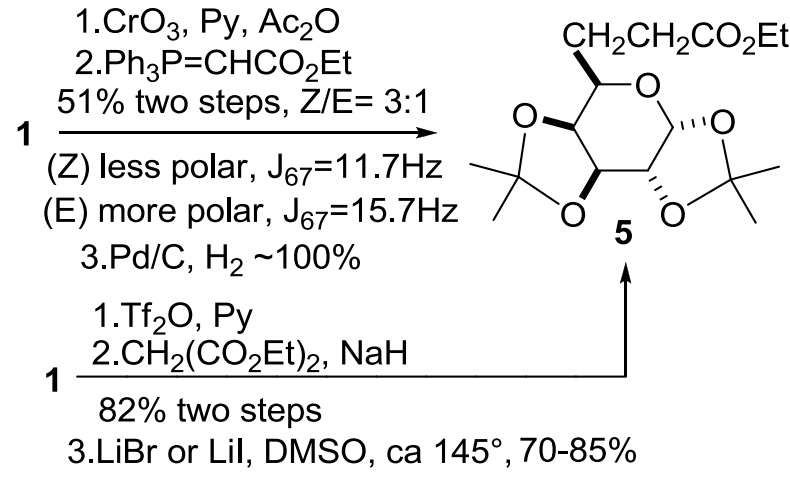

Scheme 2. Two atoms extension in 1.

5 was used to get $\mathbf{6}$ with two more $\mathrm{C}$ atoms in a side chain (Scheme 3):

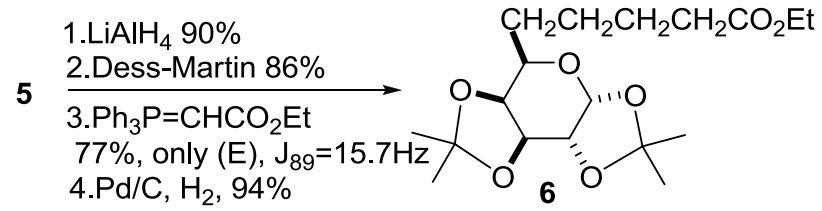

Scheme 3. Four atoms extension in 1.

The compounds 5 and $\mathbf{6}$ will be used to obtain the targets $(R)-7$ by analogy to the procedure shown in the Scheme 1.<smiles>C=C[C@H](CO)C(O)CC(=O)OCC</smiles>

(R) $7 \mathrm{n}=2,4$

\section{CONCLUSION}

C5 atom in D-galactopyranose was used as a source of chirality to obtain the $(S)$ glycerol 4 . Side chain extended D-galacto compounds 5 and $\mathbf{6}$ were obtained. Their application to get the diols $(R) 7$ will be reported in due course.

\section{REFERENCES}

${ }^{1}$ Knauer, S.; Kranke, B.; Krause, L.; Kunz, H. Curr.Org.Chem. 2004, 8 1739

1739.
2 Liu, W. "Terpenes: The Expansion of the Chiral Pool" in "Handbook of Chiral Chemicals"; $2^{\text {nd }}$ ed.; Ager, D. Ed.; CRC Press: Boca Raton, 2005, p.59.

3.Williams, R.M.; Burnett, C.M. ACS Symp.Ser. 2009, 1009, 420. 